\title{
Inventarizacija voćnih vrsta i ukrasne dendroflore u vrtovima grada Skradina
}

\author{
Inventory of fruit species and ornamental arboreal plants \\ in the gardens of the town of Skradin
}

B. Dorbić, J. Gverić, Emilija Friganović

\section{SAŽETAK}

U radu su prikazani rezultati istraživanja dendroflore vrtova na području grada Skradina, koji je smješten u sjevernoj Dalmaciji, na desnoj obali rijeke Krke, u Šibensko-kninskoj županiji. Grad Skradin obuhvaća prostor od $186,79 \mathrm{~km}^{2}$ na kojem se nalazi 21 naselje. Urbani vrtovi na području grada Skradina su uglavnom neformalno oblikovani i uređeni. U njima su zasađene utilitarne i dekorativne vrste i u globalu ne posjeduju dobre kompozicijske karakteristike.

Tijekom florističkog istraživanja u svibnju 2016. godine, analizirani su skradinski vrtovi različite veličine te je zabilježeno 74 svojti s dominacijom kritosjemenjača (66 svojti; 89,19\%), među kojima su dvosupnice (59; 79,73 \%) u većoj mjeri zastupljenije od jednosupnica $(7 ; 9,46 \%)$. Golosjemenjače su zastupljene s 8 svojti $(10,81 \%)$. Svojte su svrstane u 36 porodica. Porodica Rosaceae se ističe s najvećim brojem vrsta (13 vrsta; 17,57 \%). U pogledu analize dendroflore s obzirom na tip habitusa (po Erhardtu i sur., 2002) dominiraju grmolike forme (33 svojte; 44,59 \%), potom slijede stabla (31 svojta; 41,89\%), polugrmovi (3 svojte; 4,05\%), polugrmovisukulente (1 svojta; 1,35 \%) i penjačice (6 svojti; 8,11 \%). Zimzelene svojte $(41 ; 55,40 \%)$ su zastupljenije od listopadnih $(33 ; 44,59 \%)$. Od 74 svojte u istraženoj dendroflori Skradina 15 svojti $(20,27 \%)$ su autohtone.

Ključne riječi: dendroflora, inventarizacija,vrtovi, Skradin.

\section{ABSTRACT}

The paper presents research results concerning the ornamental arboreal plants in gardens on the territory of the town of Skradin, located in Northern Dalmatia, on the right bank of the Krka River, in Šibenik-Knin County. The town of Skradin covers an area of $186.79 \mathrm{~km}^{2}$ where 21 settlements are located. Urban gardens in the territory of Skradin are mostly informally designed and landscaped. Utilitarian and ornamental species have been planted and in general they do not show good compositional features.

During the floristic research conducted in May 2016, Skradin gradens of diverse size were analysed and 74 species were recorded with the predominance of 
Angiospermae (66 species; $89.19 \%$ ), amongst which Dicotyledoneae (59; $79.73 \%$ ) exceeded Monocotyledoneae $(7 ; 9.46 \%)$. Gymnospermae were represented with 8 species $(10.81 \%)$. The species were grouped into 36 families. The Rosaceae family stands out with the greatest number of species (13 species; $17.57 \%$ ). Upon the dendroflora analysis concerning the type of habitas (according to Erhardt et al.., 2002) shrub-like forms are dominant (33 species; $44.59 \%$ ), followed by trees (31 species; $41.89 \%$ ), half shrubs (3 species; $4.05 \%$ ), half shrubs-succulents (1 species; $1.35 \%$ ) and creepers ( 6 species; $8.11 \%)$. Coniferous species $(41 ; 55.40 \%)$ are more frequent compared with deciduous species $(33 ; 44.59 \%)$. Out of 74 species amongst the analysed dendroflora in Skradin 15 species $(20.27 \%$ ) are autochthonous.

Key words: arboreal plants, inventory, gardens, Skradin.

\section{UVOD}

Uzgoj različitih mediteranskih voćnih i ukrasnih kultura na području grada Skradina ima dugu tradiciju. Od davnina se na ovom prostoru uzgajaju sljedeće voćne kulture: maslina, žižula, badem, smokva ${ }^{1}$, vinova loza, bijeli i crni dud, različite vrste agruma i dr. Dudovi (crni i bijeli) su se počeli saditi već u 19. stoljeću, a istinski napredak svilarstvo, zbog kojeg se bijeli dud i uzgajao u Skradinu, doživljava nakon 1854. godine. Glavni skradinski đardin posjeduje popriličan broj vrijednih starih stabala crnog i bijelog duda, kao i glavna prometnica uz obalu. U Skradinu postoji i ulica Skradinskih svilara uzduž koje su zasnovani drvoredi od bijele i crne murve (Dorbić i sur., 2013.).

Za skradinsko područje je karakteristična i žižula, koja ima dugu tradiciju uzgoja u skradinskim vrtovima, a po narodnoj predaji se smatra da su je u Skradin donijeli pomorci. Gotovo da i nema vrta u Skradinu u kojem se ne uzgaja ova voćna vrsta. Mora se istaknuti i košćela koja je osim za hladovinu, bila korisna i za ljudsku ishranu (plodovi), za vrijeme minulih ratova iz 20. stoljeća.

Prostor grada Skradina je područje između srednjeg i sjevernog dijela Dalmacije. Skradinsko područje je relativno niski krški zagorski prostor. Područje dostiže svoju najveću visinu na sjeverozapadnom dijelu u Bribirskoj glavi (298 m. n. v.). Od plodnih poljoprivrednih područja ističu se Skradinsko i Bribirsko polje. Klima je mediteranska, ali ponešto modificirana kontinentalnim utjecajima iz dinarskog zaleđa. $^{2}$

\footnotetext{
${ }^{1}$ O dendrološko-krajobraznoj valorizacije smokve u vrtovima Šibenika, više u Dorbić i Temim, 2015.

${ }^{2} \mathrm{http}: / /$ www.urbing.com/web/stranice/ppug_1.htm 92
} 
U Skradinu se osim korisnih vrsta uzgaja i različito ukrasno bilje, po njegovim đardinima, trgovima, kao linijsko zelenilo, vrtovima ${ }^{3}$ itd. Urbani vrtovi u samom središtu grada i bližem okruženju uglavnom su neformalno uređeni. To su vrtovi različitih formi i veličina. U njima su posađene utilitarne $\mathrm{i}$ dekorativne vrste i u globalu ne posjeduju dobre kompozicijske karakteristike. Održavanje zelenih površina je na razini prosječnosti.

Istraživanjem urbane flore (samonikle i hortikulturne vrste) nekih dalmatinskih gradova bavili su se sljedeći autori: Šibenika (Milović, 2000.), Splita (Ruščić, 2002.), Zadra (Milović, 2008. i Perinčić, 2010.), Omiša (Tafra, 2009.), Knina (Dorbić i sur., 2014.).

U krajobrazno uređenje poželjno je uvoditi i naše autohtone dendrološke vrste (Židovec i Karlović, 2005., Dorbić i sur., 2012.).

Cilj rada je inventarizacija ukrasne dendroflore u odabranim vrtovima na području grada Skradina.

\section{MATERIJAL I METODE}

U radu je inventarizirana dendroflora na području grada Skradina (Slika 1). Tijekom terenskih istraživanja u svibnju 2016. godine analizirano je 45 vrtova različitih veličina.

Pri determinaciji biljnih vrsta korištena je sljedeća floristička literatura: Tutin, 1980.; Walters, 1986.; Walters, 1989.; Domac, 1994.; Erhardt i sur., 2002.; Vidaković i Franjić, 2004.; Idžojtić, 2009. Nomenklatura svojti u popisu flore usklađena je prema Nikoliću (2012.). Hrvatsko nazivlje svojti je prema: Domac (1994.); Vidaković i Franjić (2004.); Idžojtić (2009.).

$\mathrm{U}$ popisu flore, vrste i podvrste prikazane su abecednim redom u okviru porodica i viših sistematskih kategorija. Za svaku svojtu navedeni su sljedeći podaci: hrvatsko i znanstveno ime, oznaka da li se radi o domaćoj (autohtonoj) ili stranoj (alohtonoj) svojti, oblik habitusa, te je li vrsta listopadna ili vazdazelena.

Razdioba životnih oblika obavljena je prema Erhardtu i sur. (2002.), dok se u popisu flore navode sljedeće kratice: G-grm, Gna-polugrm, Gsu-grmsukulentni, G/S-grm ili stablo, S/G-stablo ili grm, S-stablo, Li-penjačica (lijana). Raspodjela svojti na listopadne (L) i vazdazelene (V). Dendroflora

\footnotetext{
${ }^{3}$ Osim terapeutske i socijalne vrijednosti vrt ima estetsku, gospodarsku i ekološku vrijednost. On uljepšava okućnicu, daje posebnu raskoš užitku stanovanja u privatnoj kući te je vrlo važan zbog mogućnosti uzgoja korisnih i jestivih biljaka (Aničić, 2003.).

${ }^{4}$ I u većim gradovima u Županiji poput Šibenika u prošlosti i novijem vremenskom razdoblju nije se odveć značaja davalo oblikovanju i održavanju krajobraznih površina (Dorbić i Temim, 2015.; Dorbić i Temim, 2016.).
} 
B. Dorbić i sur.: Inventarizacija voćnih vrsta i ukrasne dendroflore u vrtovima grada Skradina

Skradina je s obzirom na podrijetlo svojti razvrstana na autohtone (AU) ili alohtone svojte (AL). Autohtone (čiji je prirodni areal u cijelosti ili barem jednim dijelom unutar granica Hrvatske) i alohtone svojte (čiji je prirodni areal izvan granica Hrvatske).

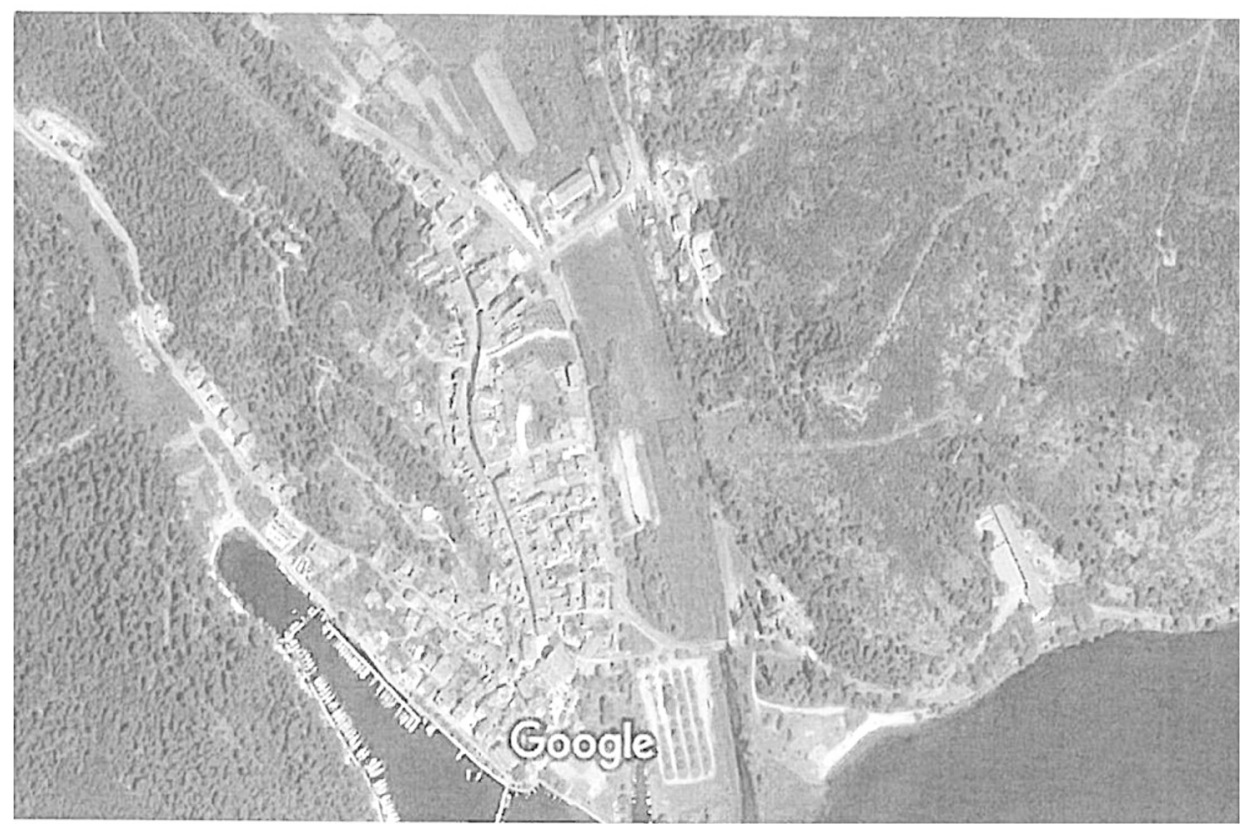

Slika 1. Snimak istraživanih vrtova na području Skradina (Google maps)

Figure 1. Snapshot of researched gardens in the area of Skradin (Google maps)

\section{REZULTATI}

Popis flore

Popis dendroflore istraživanih vrtova na području grada Skradina dan je u Tablici 1. 
B. Dorbić i sur.: Inventarizacija voćnih vrsta i ukrasne dendroflore u vrtovima grada Skradina

Tablica 1. Popis dendroflore u istraživanim vrtovima grada Skradina (Autori)

Table 1. List of arboreal plants in the researched gardens of Skradin (Authors)

\begin{tabular}{|c|c|c|c|c|c|}
\hline $\begin{array}{c}\text { Redni } \\
\text { broj }\end{array}$ & Hrvatski i latinski naziv vrste & Porodica & \multicolumn{3}{|c|}{ Opis vrste } \\
\hline \multicolumn{6}{|c|}{ SPERMATOPHYTA / GYMNOSPERMAE / CONIFEROPSIDA/ CYCADOPSIDA } \\
\hline 1. & $\begin{array}{l}\text { Lavsonov pačempres (Chamaecyparis } \\
\text { lawsoniana A. Murray) }\end{array}$ & Cupressaceae & $\mathrm{S}$ & $\mathrm{V}$ & $\mathrm{AL}$ \\
\hline 2. & Čempres (Cupressus sempervirens L.) & Cupressaceae & $\mathrm{S}$ & $\mathrm{V}$ & $\mathrm{AU}$ \\
\hline 3. & Američka tuja (Thuja occidentalis L.) & Cupressaceae & $\mathrm{S}$ & $\mathrm{V}$ & AL \\
\hline 4. & Istočna tuja (Thuja orientalis L.) & Cupressaceae & $\mathrm{G} / \mathrm{S}$ & $\mathrm{V}$ & $\mathrm{AL}$ \\
\hline 5. & Grčka jela (Abies cephalonica Loudon) & Pinaceae & $\mathrm{S}$ & $\mathrm{V}$ & $\mathrm{AL}$ \\
\hline 6. & Smreka (Picea abies L.) & Pinaceae & $\mathrm{S}$ & $\mathrm{V}$ & $\mathrm{AU}$ \\
\hline 7. & Alepski bor (Pinus halepensis Mill.) & Pinaceae & $\mathrm{S}$ & $\mathrm{V}$ & $\mathrm{AU}$ \\
\hline 8. & Cikas (Cycas revoluta Thunb.) & Cycadaceae & $\mathrm{S}$ & $\mathrm{V}$ & $\mathrm{AL}$ \\
\hline \multicolumn{6}{|c|}{ ANGIOSPERMAE / MAGNOLIOPSIDA (DICOTYLEDONES) } \\
\hline 9. & Javor negundovac (Acer negundo L.) & Acearaceae & $\mathrm{S}$ & $\mathrm{L}$ & $\mathrm{AL}$ \\
\hline 10. & Javor mliječ (Acer platanoides L.) & Acearaceae & $\mathrm{S}$ & $\mathrm{L}$ & $\mathrm{AL}$ \\
\hline 11. & $\begin{array}{l}\text { Kiwi (Actinidia deliciosa (C. F. Liang \& A. R. } \\
\text { Ferguson) }\end{array}$ & Actinidiacae & $\mathrm{L}$ & $\mathrm{L}$ & $\mathrm{AL}$ \\
\hline 12. & Oleandar (Nerium oleander L.) & Apocynaceae & G & $\mathrm{V}$ & $\mathrm{AU}$ \\
\hline 13. & $\begin{array}{l}\text { Zimzeleni jasmin (Trachelospermum } \\
\text { jasminoides (Lindl.) Lem.) }\end{array}$ & Apocynaceae & $\mathrm{L}$ & $\mathrm{V}$ & AL \\
\hline 14. & Bršljan (Hedera helix L.) & Araliaceae & $\mathrm{L}$ & $\mathrm{V}$ & $\mathrm{AU}$ \\
\hline 15. & Božikovina (Ilex aquifolium $\mathrm{L}$.) & Aquifoliaceae & $\mathrm{G} / \mathrm{S}$ & $\mathrm{V}$ & $\mathrm{AL}$ \\
\hline 16. & Šimšir (Buxus sempervirens L.) & Buxaceae & $\mathrm{G}$ & $\mathrm{V}$ & $\mathrm{AL}$ \\
\hline 17. & Tekoma (Campsis radicans (L.) Seen.) & Bignoniaceae & $\mathrm{L}$ & $\mathrm{L}$ & $\mathrm{AL}$ \\
\hline 18. & Opuncija (Opuntia ficus-indica (L.) Miller & Cactaceae & Gsu & $\mathrm{V}$ & $\mathrm{AL}$ \\
\hline 19. & $\begin{array}{l}\text { Kolkvicija (Kolkwitzia amabilis } \\
\text { (Graebn.) Christenh.) }\end{array}$ & Caprifoliaceae & $\mathrm{G}$ & $\mathrm{V}$ & AL \\
\hline 20. & Lemprika (Viburnum tinus L.) & Caprifoliaceae & G & $\mathrm{V}$ & $\mathrm{AU}$ \\
\hline 21. & Judino drvo (Cercis siliquastrum L.) & Fabaceae & $\mathrm{S}$ & $\mathrm{L}$ & $\mathrm{AL}$ \\
\hline 22. & Aucuba (Aucuba japonica Thunb.) & Garryaceae & G & $\mathrm{V}$ & $\mathrm{AL}$ \\
\hline 23. & $\begin{array}{l}\text { Hortenzija (Hydrangea macrophylla } \\
\text { Thumb. Ex Murray) Ser.) }\end{array}$ & Hydrangeaceae & G & $\mathrm{L}$ & $\mathrm{AL}$ \\
\hline 24. & Orah (Juglans regia L.) & Juglandaceae & $\mathrm{S}$ & $\mathrm{L}$ & $\mathrm{AL}$ \\
\hline 25. & Lavanda (Lavandula angustifolia Mill.) & Lamiaceae & G & $\mathrm{V}$ & $\mathrm{AL}$ \\
\hline 26. & Francuska lavanda (Lavandula dentata L.) & Lamiaceae & Gna & $\mathrm{V}$ & $\mathrm{AL}$ \\
\hline 27. & Ružmarin (Rosmarimus officinalis L.) & Lamiaceae & $\mathrm{G}$ & $\mathrm{V}$ & $\mathrm{AU}$ \\
\hline 28. & Kadulja (Salvia officinalis L.) & Lamiaceae & Gna & $\mathrm{V}$ & $\mathrm{AU}$ \\
\hline 29. & Čubar (Satureja hortensis L.) & Lamiaceae & Gna & $\mathrm{V}$ & $\mathrm{AU}$ \\
\hline 30. & Lovor (Laurus nobilis L.) & Lauraceae & $\mathrm{G} / \mathrm{S}$ & $\mathrm{V}$ & $\mathrm{AU}$ \\
\hline 31. & Sirijski hibiskus (Hibiscus syriacus L.) & Malvaceae & $\mathrm{G}$ & $\mathrm{L}$ & $\mathrm{AL}$ \\
\hline 32. & Očenašica (Melia azedarach L.) & Meliaceae & $\mathrm{S}$ & $\mathrm{L}$ & $\mathrm{AL}$ \\
\hline 33. & Feijoa (Acca sellowiana (O. Berg.) & Myrtaceae & $\mathrm{G} / \mathrm{S}$ & $\mathrm{V}$ & $\mathrm{AL}$ \\
\hline 34. & Cetkavac (Callistemon citrinus (Curtis) Skeels) & Myrtaceae & $\mathrm{G}$ & $\mathrm{V}$ & AL \\
\hline 35. & Dudovac (Broussonetia papyrifera (L.) Vent.) & Moraceae & $\mathrm{S}$ & $\mathrm{V}$ & $\mathrm{AL}$ \\
\hline 36. & Smokva (Ficus carica L.) & Moraceae & $\mathrm{S}$ & $\mathrm{L}$ & $\mathrm{AL}$ \\
\hline 37. & Bijeli dud (Morus alba L.) & Moraceae & $\mathrm{S}$ & $\mathrm{L}$ & $\mathrm{AL}$ \\
\hline 38. & Crni dud (Morus nigra L.) & Moraceae & $\mathrm{S}$ & $\mathrm{L}$ & $\mathrm{AL}$ \\
\hline
\end{tabular}


B. Dorbić i sur.: Inventarizacija voćnih vrsta i ukrasne dendroflore u vrtovima grada Skradina

\begin{tabular}{|c|c|c|c|c|c|}
\hline $\begin{array}{c}\text { Redni } \\
\text { broj }\end{array}$ & Hrvatski i latinski naziv vrste & Porodica & \multicolumn{3}{|c|}{ Opis vrste } \\
\hline 39. & Zimzelena kalina (Ligustrum ovalifolium Hassk.) & Oleaceae & $\mathrm{G} / \mathrm{S}$ & $\mathrm{V}$ & $\mathrm{AL}$ \\
\hline 40. & Maslina (Olea europaea L.) & Oleaceae & $\mathrm{G} / \mathrm{S}$ & $\mathrm{V}$ & $\mathrm{AU}$ \\
\hline 41. & Jorgovan (Syringa vulgaris Mill.) & Oleaceae & $\mathrm{G} / \mathrm{S}$ & $\mathrm{L}$ & $\mathrm{AL}$ \\
\hline 42. & Paulovnija (Paulownia tomentosa Steud.) & Paulowniaceae & $\mathrm{S}$ & $\mathrm{L}$ & $\mathrm{AL}$ \\
\hline 43. & Pitospora (Pittosporum tobira W. T. Ai ton) & Pittosporaceae & $\mathrm{G} / \mathrm{S}$ & $\mathrm{V}$ & $\mathrm{AL}$ \\
\hline 44. & Šipak (Punica granatum L.) & Punicaceae & $\mathrm{G} / \mathrm{S}$ & $\mathrm{L}$ & AL \\
\hline 45. & Žižula (Ziziphus jujuba Mill.) & Rhamnaceae & $\mathrm{G} / \mathrm{S}$ & $\mathrm{L}$ & $\mathrm{AL}$ \\
\hline 46. & Dunja (Cydonia oblonga Mill.) & Rosaceae & $\mathrm{G} / \mathrm{S}$ & $\mathrm{L}$ & $\mathrm{AL}$ \\
\hline 47. & $\begin{array}{l}\text { Japanska nešpula (Eriobotryia japonica (Thunb.) } \\
\text { Lindl.) }\end{array}$ & Rosaceae & $\mathrm{S} / \mathrm{G}$ & V & AL \\
\hline 48. & Jabuka (Malus domestica (Borkh.) & Rosaceae & $\mathrm{S}$ & $\mathrm{L}$ & $\mathrm{AL}$ \\
\hline 49. & Marelica (Prumus armeniaca L.) & Rosaceae & $\mathrm{S}$ & $\mathrm{L}$ & $\mathrm{AL}$ \\
\hline 50. & Džanarika (Prunus cerasifera Ehrh.) & Rosaceae & $\mathrm{G} / \mathrm{S}$ & $\mathrm{L}$ & AL \\
\hline 51. & Višnja (Prumus cerasus L.) & Rosaceae & $\mathrm{S} / \mathrm{G}$ & $\mathrm{L}$ & $\mathrm{AL}$ \\
\hline 52. & Šljiva (Prunus domestica L.) & Rosaceae & $\mathrm{S}$ & $\mathrm{L}$ & $\mathrm{AL}$ \\
\hline 53. & Badem (Prumus dulcis (Mill.) D. A. Webb.) & Rosaceae & $\mathrm{S}$ & $\mathrm{L}$ & $\mathrm{AL}$ \\
\hline 54. & Breskva (Prunus persica (L.) Batsch) & Rosaceae & $\mathrm{S}$ & $\mathrm{L}$ & $\mathrm{AL}$ \\
\hline 55. & Kruška (Pyrus communis L.) & Rosaceae & $\mathrm{S}$ & $\mathrm{L}$ & $\mathrm{AL}$ \\
\hline 56. & Ruža (Rosa x hybrida L.) & Rosaceae & G & $\mathrm{L}$ & AL \\
\hline 57. & Kupina (Rubus fruticosus L.) & Rosaceae & $\mathrm{G}$ & $\mathrm{L}$ & $\mathrm{AL}$ \\
\hline 58. & Oskoruša (Sorbus domestica L.) & Rosaceae & $\mathrm{S}$ & $\mathrm{L}$ & $\mathrm{AU}$ \\
\hline 59. & Limun $($ Citrus $\times$ limon (L.) Burm F.) & Rutaceae & $\mathrm{G}$ & $\mathrm{V}$ & $\mathrm{AL}$ \\
\hline 60. & Mandarina (Citrus reticulata L.) & Rutaceae & $\mathrm{G}$ & $\mathrm{V}$ & $\mathrm{AL}$ \\
\hline 61. & Naranča (Citrus x sinensis (L.) Osbeck & Rutaceae & $\mathrm{G}$ & $\mathrm{V}$ & $\mathrm{AL}$ \\
\hline 62. & $\begin{array}{l}\text { Kunkvat (Fortunella japonica (Thunb.) } \\
\text { Swingle) }\end{array}$ & Rutaceae & G & $\mathrm{V}$ & AL \\
\hline 63. & Žalosna vrba (Salix babylonica L.) & Salicaceae & $\mathrm{S}$ & $\mathrm{L}$ & $\mathrm{AL}$ \\
\hline 64. & Pajasen (Ailanthus altissima (Mill.) Swingle.) & Simaroubaceae & $\mathrm{S}$ & $\mathrm{L}$ & $\mathrm{AL}$ \\
\hline 65. & Košćela (Celtis australis L.) & Ulmaceae & $\mathrm{S}$ & $\mathrm{L}$ & $\mathrm{AU}$ \\
\hline 66. & $\begin{array}{l}\text { Peterolisna lozica (Parthenocissus quinquefolia } \\
\text { (L.) Planch) }\end{array}$ & Vitaceae & $\mathrm{L}$ & $\mathrm{L}$ & AL \\
\hline 67. & Vinova loza (Vitis vinifera $\mathrm{L}$ ) & Vitaceae & $\mathrm{L}$ & $\mathrm{L}$ & $\mathrm{AL}$ \\
\hline \multicolumn{6}{|c|}{ LILIOPSIDA (MONOCOTYLEDONES) } \\
\hline 68. & Agava (Agave americana L.) & Asparagaceae & G & $\mathrm{V}$ & $\mathrm{AL}$ \\
\hline 69. & Svečana juka (Yucca gloriosa L.) & Asparagaceae & G & $\mathrm{V}$ & $\mathrm{AL}$ \\
\hline 70. & Niska žumara (Chamareops humilis L.) & Areaceae & $\mathrm{G} / \mathrm{S}$ & $\mathrm{V}$ & $\mathrm{AU}$ \\
\hline 71. & Kanarska datulja (Phoenix canariensis Chabaud) & Areaceae & $\mathrm{S}$ & $\mathrm{V}$ & $\mathrm{AL}$ \\
\hline 72. & $\begin{array}{l}\text { Visoka Žumara (Trachycarpus fortunei (Hook) } \\
\text { H.Wendl.) }\end{array}$ & Areaceae & $\mathrm{S}$ & $\mathrm{V}$ & AL \\
\hline 73. & $\begin{array}{l}\text { Pampas trava (Cortaderia selloana (Schult. \& } \\
\text { Schult. f.) Asch. \& Graebn) }\end{array}$ & Poaceae & G & $\mathrm{V}$ & $\mathrm{AL}$ \\
\hline 74. & $\begin{array}{l}\text { Crni bambus (Phyllostachys bambusoides } \\
\text { Siebold i Zucc.) }\end{array}$ & Poaceae & G & $\mathrm{V}$ & $\mathrm{AL}$ \\
\hline
\end{tabular}

Taksonomskom analizom dendroflore Skradina (Tablica 1.) obuhvaćeno je 74 svojti gdje dominiraju kritosjemenjače (66 svojti; 89,19 \%), među kojima su dvosupnice $(59 ; 79,73 \%)$ u većoj mjeri zastupljenije od jednosupnica $(7 ; 9$, $46 \%)$. 
Dominacija kritosjemenjača zabilježena je i na području grada Rijeke (70; 12 \%) Karavla (1997.); Omiša, Tafra, Pandža, Milović (2012.); Knina, Dorbić i sur., (2014.). Golosjemenjače su zastupljene s 8 svojti (10,81\%). Svojte su svrstane u 36 porodica. Porodica Rosaceae se ističe s najvećim brojem vrsta (13 vrsta; $17,57 \%)$.

Analizirajući dendrofloru s obzirom na tip habitusa (po Erhardtu i sur., 2002.) pokazuje se dominacija grmolikih formi (33 svojti; 44,59\%), potom slijede stabla (31 svojti; 41,89\%), polugrmovi (3 svojte; 4,05\%), polugrmovisukulente (1 svojta; $1,35 \%$ ) i penjačice (6 svojti; 8,11\%). Tafra, Pandža, Milović (2012.) u dendroflori Omiša također navode veću primjenu grmolikih formi u krajobraznom uređenju.

Zimzelene svojte $(41 ; 55,40 \%)$ su zastupljenije od listopadnih $(33 ; 44,59$ $\%)$. Od 74 svojte u istraženoj dendroflori Skradina 15 svojti $(20,27 \%)$ su autohtone. Dominacija alohtonih nad autohtonim vrstama zabilježena je i u flori Vukovara (Rauš, 1969.), Rijeke (Karavla i sur., 1997.), Omiša (Tafra, Pandža, Milović, 2012.), Knina (Dorbić i sur., 2014.).

\section{ZAKLJUČAK}

Uzgoj različitih voćnih vrsta u vrtovima na području grada Skradina ima dugu tradiciju. Na ovom području se od davnina uzgajaju sljedeće voćne kulture: maslina, žižula, badem, vinova loza, bijeli i crni dud, različite vrste agruma i dr. Osim navedenih vrsta od 20. stoljeća u vrtovima se intenzivnije počinju uzgajati i različite mediteranske ukrasne drvenaste vrste.

Uređenje i oblikovanje vrtova na području grada Skradina je uglavnom amatersko. Izbor vrsta $\mathrm{i}$ uređenje vrtnih prostora je povezano $\mathrm{s}$ osobnim preferencijama vlasnika. Kroz krajobrazno uređenje potrebno je uvoditi naše autohtone voćne i ukrasne vrste.

U radu je izvršena inventarizacija dendroflore vrtova na području grada Skradina, tijekom svibnja 2016. godine.

Taksonomskom analizom dendroflore Skradina obuhvaćeno je 74 svojte gdje dominiraju kritosjemenjače (66 svojti; 89,19\%). Svojte su svrstane u 36 porodica. Porodica Rosaceae se ističe s najvećim brojem vrsta (13 vrsta; 17 , $57 \%$ ). Pokazuje se dominacija grmolikih formi (33 svojti; 44,59\%). Zimzelene svojte $(41 ; 55,40 \%)$ su zastupljenije od listopadnih (33; 44,59\%). Od 74 svojte u istraženoj dendroflori Skradina 15 svojti $(20,27 \%)$ su autohtone. 
Napomena:

Rad je izvod iz Završnog rada Josipa Gverića pod naslovom: „Inventarizacija dendroflore u vrtovima grada Skradina.“

\section{LITERATURA}

ANIČIĆ, B. (2002.). Usporedba tradicionalne i suvremene kulture stanovanja u jednoobiteljskom boravištu na osnovi odnosa kuća-vrt, Studia ethnologica Croatica 14/15: 185-212.

DOMAC, R. (1994.). Flora Hrvatske, Priručnik za određivanje bilja, Zagreb.

DORBIĆ, B., GAĆINA, N., KRNČEVIĆ, M., KRNČEVIĆ, Ž., SRPAK, M. (2012.). Značaj krajobraznog oblikovanja u ekološkoj proizvodnji meda na području Srime kod Šibenika, Zbornik radova Međimurskog veleučilišta u Čakovcu br. 2: 33-41.

DORBIĆ, B., GARDIJAN, P., TEMIM, E., HADŽIABULIĆ, A., KRNČEVIĆRAK, M. (2013.). Pejzažne karakteristike murve (Morus alba L.) u turističkom identitetu Skradina, 1. Znanstvenostručna konferencija s međunarodnim sudjelovanjem „Izazovi današnjice-Turizam danas za sutra“: Zbornik radova. Veleučilište u Šibeniku: 515-522.

DORBIĆ, B., ŠOLIĆ, I., GUGIĆ, M., TEMIM, E., ŠAROLIĆ, M., ŠUSTE, M. (2014.). Inventarizacija voćnih vrsta i ukrasne dendroflore u privatnim vrtovima na području grada Knina, Pomologia Croatica, Vol. 20 No. 1-4: 43-56

DORBIĆ, B., TEMIM, E. (2015-a.). Dendrological landscape valorisation of the common fig (Ficus carica L.) in the gardens of Šibenik, Works of the Faculty of Forestry University of Sarajevo. No. 2: 25-36.

DORBIĆ, B., TEMIM, E. (2015-b.). Povijesni pregled razvoja vrtlarstva i krajobraznog uređenja Šibenika i okolice u razdoblju 1945.-1985. godine, Annals for Istrian and Mediterranean studies-Series Historia et Sociologia, 25, 2015, 3: 637-650.

DORBIĆ, B., TEMIM, E. (2016.). Povijesni pregled razvoja vrtlarstva i krajobraznog uređenja Šibenika i okolice u razdoblju 1880.-1945. godine, Annals for Istrian and Mediterranean studies-Series Historia et Sociologia, 26, 2: 227-246.

EERHARDT, W., GOTZ, E., BODEKER, N., SEYBOLD, S. (2002.). Zander, Handworterbuch der Pflanzennamen. 17. Auf. Eugen Ulmer, Stuttgart. 
HULINA, N. (2011.). Više biljke stablašice, Golden Marketing-Tehnička knjiga, Zagreb.

IDŽOJTIĆ, M. (2009.). Dendrologija-list, Sveučilište u Zagrebu, Šumarski fakultet. Zagreb.

KARAVLA, J. (1997). Parkovni objekti u općini Rijeka, Šumarski list 121 (34): $133-160$.

MILOVIĆ, M. (2000.). Flora papratnjača i sjemenjača Šibenika i okolice, Magistarski rad. Biološki odsjek, Prirodoslovno-matematički fakultet Sveučilišta u Zagrebu, Zagreb.

MILOVIĆ, M. (2008.). Urbana flora Zadra. Disertacija, Biološki odsjek, Prirodoslovno-matematički fakultet Sveučilišta u Zagrebu, Zagreb.

MITIĆ, B., BORŠIĆ, I., DUJMOVIĆ, S., BOGDANOVIĆ, M., MILOVIĆ, M., CIGIĆ, P., REŠETNIK, I., NIKOLIĆ, T. (2008.). Alien flora of Croatia: prosals for standards in terminology, criteria and related dana base, Natura Croatica. 17 (2): 73-90.

NIKOLIĆ, T. (ed.) (2012.). Flora Croatica baza podataka/Flora Croatica Database. On-Line URL: http://hirc.botanic.hr/fcd. Botanički zavod s Botaničkim vrtom, Prirodoslovno-matematički fakultet, Sveučilište u Zagrebu.

PERINČIĆ, B. (2010.). Hortikulturna flora Zadra, Magistarski rad, Biološki odsjek. Prirodoslovno-matematički fakultet Sveučilišta u Zagrebu, Zagreb.

RAUŠ, Đ. (1969.). Autohtona i alohtona dendroflora šire okolice Vukovara, Šumarski list 5-6: 185-209.

RUŠČIĆ, M. (2002.). Urbana flora Splita, Magistarski rad, Biološki odsjek, Prirodoslovno-matematički fakultet Sveučilišta u Zagrebu, Zagreb.

ŠILIĆ, Ć. (1990.). Ukrasno drveće i grmlje, IP. Svjetlost, Sarajevo.

TAFRA, D. (2009.). Vaskularna flora Omiša, Magistarski rad, Šumarski fakultet Sveučilišta u Zagrebu.

TAFRA, D., PANDŽA, M., MILOVIĆ, M. (2012.). Dendroflora Omiša, Šumarski list. 11-12: 605-617.

TUTIN, T. G., HEYWOOD, V. T., BURGES, N. A., MOORE, D. M., VALENTINE, D. H., WALTERS, S. M., WEBB, D. A. (EDS). (1964.1980.). Flora europea 1-5, Cambridge University Press, Cambridge. 
VIDAKOVIĆ, M., FRANJIĆ, J. (2004.). Golosjemenjače, Šumarski fakultet Zagreb.

WALTERS, S. M., BRADY, A., BRICKELL, C. D., CULLEN, J., GREEN, P. S., LEWIS, J., MATTHEWS, V. A., WEBB, D. A., YEO, P. F., ALEXANDER, J. C. M. (EDS). (1984.-1986.). The European Garden Flora, I-II, Cambridge University Press, Cambridge.

WALTERS, S. M., BRADY, A., BRICKELL, C. D., CULLEN, J., GREEN, P. S., LEWIS, J., MATTHEWS, V. A., WEBB, D. A., YEO, P. F., ALEXANDER, J. C. M. (EDS). (1989.). The European Garden Flora, III, Cambridge University Press, Cambridge.

ŽIDOVEC, V., KARLOVIĆ, K. (2005.). Primjena autohtonog bilja u uređenju gradskih prostora, Agronomski glasnik, br. 2-4: 151.

http://www.urbing.com/web/stranice/ppug_1.htm (Preuzeto: 28.08.2016.)

\section{Adresa autora - Author's address:}

dr. sc. Boris Dorbić, pred.

Emilija Friganović, v. pred.

Josip Gverić, diplomant

Veleučilište „Marko Marulić“ u Kninu, odjel Poljoprivreda krša, Krešimirova 30 a, 22300 Knin. 